\title{
Representation of the Diurnal Distribution of Organic Aerosol by Multidimensional Liquid Chromatography Systems
}

\author{
Organik Aerosolün Çok Boyutlu Sıvı Kromatografi Sistemleri ile Günlük Dağılımının \\ Gösterimi
}

Elif MERTOĞLU1 ${ }^{1}$ (D), Rosa M. FLORES ${ }^{1}$ (iD)

${ }^{1}$ Marmara University, Environmental Engineering Department, 34722, Istanbul, Turkey

\begin{abstract}
Aerosols have various effects on human health, climate, and ecosystems. Aerosols also have an important role in climate change by altering the radiation balance and lifetime and properties of clouds. Organic aerosol (OA) is composed of a mixture of hundreds to thousands of organic compounds that varies geographically, diurnally, and seasonally according to several factors, such as type and concentration of precursor, type and concentration of oxidants, temperature, relative humidity, among others. The type and number of functional groups composing individual organic species influence their interaction with water vapor and sunlight, therefore affecting both the water cycle and radiation balance. Great efforts have been made to develop analytical techniques that allow the identification and quantification of individual species composing this complex mixture of organic matter and decrease the uncertainty of models to accurately predict OA formation and evolution. In this study, it was found that most of the column combinations were not adequate and the best system was provided by methanol: water (1:1). The combination of columns that provided the best separation of the standard compounds was provided by Cyclohexyl and Methyl as primary and secondary columns. However, when this combination of columns was used to represent the evolution of ambient air organic aerosols, significant co-elution was observed. The positive outcome of this study will be helpful to evaluate 2D-LC as a potential technique for more accurate determination of organic aerosol components and to understand organic aerosol formation and transformation pathways that can be used in secondary organic aerosol production models.
\end{abstract}

Keywords: multidimensional liquid chromatography, 2D-LC, organic aerosol, high-time resolved samples.

Öz

Aerosollerin; insan sağlığı, iklim ve ekosistemler üzerindeki çeşitli etkileri vardır. Ayrıca, aerosoller radyasyon dengesini ve bulutların ömür ve özelliklerini değiştirerek iklim değişikliğinde de önemli rol oynamaktadır. Organik aerosoller (OA), yüzlerce ve binlerce değişik bileşikten oluşurlar ve bu bileşikler coğrafik, gün ve mevsime göre oksidan konsantrasyonu ve türü, sıcaklık, bağıl nem gibi bir dizi faktöre bağlı olarak değişiklik gösterirler. Özgün organik türleri oluşturan fonksiyonel grupların sayısı ve tipi, aerosollerin su buharı ve güneş ışı ğı ile olan etkileşimini belirler ve bu nedenle su çevrimi ve radyasyon dengesini etkiler. Karmaşık bir karışım olan bu organik maddenin hangi türlerden oluştuğu ve bunların miktarının belirlenmesi ile OA üretimi ve gelişimini tahmin eden modellerdeki belirsizliğin azaltılması konularında büyük çabalar harcanmıştır. Bu çalışmada, kolon kombinasyonlarının çoğunun yeterli olmadığı ve en iyi sistemin metanol: su (1:1) ile sağlandığı bulundu. Standart bileşiklerin en iyi ayrışmasını sağlayan sütunların kombinasyonu, birincil ve ikincil sütunlar olarak Sikloheksil ve Metil ile sağlandı. Bununla birlikte, bu sütun kombinasyonu, ortam havası organik aerosollerinin gelişimini temsil etmek için kullanıldığında, bileşiklerin kolonlarda istenilen düzeyde ayrışmadığı gözlemlenmiştir. Bu çalışmanın çıktıları, 2D-LC yönteminin organik aerosol bileşenlerin daha doğru tespiti için potansiyel bir teknik olarak değerlendirilmesine ve ikincil organik aerosol üretim modellerinde kullanılan organik aerosol oluşumu ve dönüşüm yollarını anlamaya yardımcı olacaktır. Anahtar Kelimeler: çok boyutlu sıvı kromatografi, 2D-LC, organik aerosol, sık aralıklı toplanmış örnekler.

\section{INTRODUCTION}

Atmospheric aerosols exist in both liquid and gas phases and have numerous properties that define their impact on health, ecosystems, and climate change. Atmospheric aerosols are commonly referred as particulate matter (PM), which is classified according to the particle's aerodynamic diameter (Dp) into PM10 (Dp $<10 \mu \mathrm{m}), \mathrm{PM} 2.5$ (Dp $<$ $2.5 \mu \mathrm{m})$, and PM1 $(\mathrm{Dp}<1 \mu \mathrm{m})$. Fine particles (PM2.5) and ultrafine particles (PM1) have recently received the most attention within the scientific community due to their large atmospheric lifetimes and deeper penetration into the respiratory system[1]. It has been reported that PM is typically present in concentrations that vary between $1.000-100.000 \mathrm{~cm}-3$ and $\sim 100 \mu \mathrm{g} \mathrm{m}-3$ in continental atmospheres. Some of the effects that PM have on human health, ecosystems, and climate include aggravated respiratory illnesses, increased morbidity and mortality, atmospheric visibility reduction, acid dry and wet deposition, and alteration in the atmospheric energy budget and water cycle[2].

Corresponding Author: Rosa M. FLORES, Tel: +90 216777 3608, e-posta: rflores@marmara.edu.tr

Submitted:12.10.2020, Revised: 08.03.202I, Accepted: 09.03.2021 
Secondary organic aerosol (SOA) is the result of homogeneous nucleation of gaseous species or from the condensation of oxidized gaseous species on suspended particles. The parent hydrocarbon (HC) is a volatile organic compound (VOC) that can be oxidized in the atmosphere to produce semi-volatile organic compounds (SVOCs). SVOCs can be further oxidized to form compounds with lower volatility[3]. Oxidation at constant carbon number (nc) represents the addition of oxygen molecules into the parent hydrocarbon (HC), also known as functionalization. Reverse functionalization can be also observed in which the parent hydrocarbon loses one molecule of carbonyl or hydroxyl groups. Fragmentation reactions decrease the number of carbons followed by the addition of one or more functional groups at the site of the bond breakage. These reactions will rapidly affect the volatility of the product that will be highly oxidized. Oligomerization reactions occur when two molecules combine to form a larger molecule (i.e., polymer, P) with very low volatility[4]. Multidimensional liquid chromatography, similarly to multidimensional gas chromatography, provides enhanced resolving power by separating organic aerosol components through two columns with different separation capabilities. The main mechanism that controls the flow between the two columns is normally a multiport high-pressure switching valve with two available modes. The present work has two objectives which involve the use of a theoretical model to evaluate the use of $2 \mathrm{D}-\mathrm{LC}$ to resolve complex mixtures of organic aerosol and as means to represent diurnal variation of organic aerosol components:

Objective 1. Model the optimal separation of organic matter components in a multidimensional liquid chromatography system.

Objective 2. Represent the evolution of organic aerosol components in multidimensional liquid chromatography diagrams.

\section{MATERIALS AND METHODS}

\subsection{Construct Structure of SOA Precursors and Products}

The structures of approximately 200 biogenic and anthropogenic organic aerosol components that have been identified in chamber experiments and ambient samples were constructed with the chemistry software Chemdraw Professional v. 15.0.0.106. The SMILES notation for each structure was also predicted with Chemdraw Professional. A database with name, structure, and SMILES notation was created.

\subsection{Predict the Solvation Properties of SOA Precursors and SOA Products}

Solvation parameters for target analytes have been predicted based on their structure with Adme boxes Absolv algorithm (ACD Labs, Toronto, Canada). A database that includes structure and these predicted solvation parameters have been created. The input to the model can be SMILES notation, CAS number, a structure can be drawn with the drawing tool provided, and a library is also available. In this study, the SMILES notation has been predicted and used as input to this model.

\subsection{Model of Multidimensional Liquid Chromatography Separation}

A computer program was created using Matlab (Mathworks Inc. USA). The program includes the theory of separation in liquid chromatography based on interactions between the organic aerosol species and liquid chromatography stationary phases. The computer algorithm was based on the Abraham solvation parameter model.

The solvation parameter model used for the distribution of solutes between two condensed phases is described as follows:

$\log K_{i}=c+v V+e E+s S+a A+b B$

Where $\mathrm{K} i$ is the distribution constant or retention factor between two condensed phases. Lower case letters ( $v$, $\mathrm{e}, \mathrm{s}, \mathrm{a}$, and b) are constants that determine properties of the chromatographic column, also typically referred as system constants. Upper case letters (V, E, S, A, and B) are solute solvation parameters of target analytes in section 2.1. Both lower and upper case v, e, s, a, and b constants were determined based on molecular structures and represent intermolecular interactions. Where $\mathrm{v}$ and $\mathrm{V}$ depend on molecular size and represent cavity formation; e and $\mathrm{E}$ represent polarizability contributions from $\mathrm{n}$ - and $\pi$-electrons; $\mathrm{s}$ and $\mathrm{S}$ represent dipolarizability/polarizability, and a, A, b, and B represent hydrogen bond descriptors [5].

Solute solvation parameters were predicted with Adme Boxes Absolv module based on molecular structure. System constants have been widely reported in the literature at a single mobile phase or narrow range of compositions, including the most common mobile phases methanol-water (50:50) and acetonitrile-water (30:70) [6-13] as can be observed in Tables S1-S4 (supplementary material).

\subsection{Predict the Separation of SOA Precursors and Products in 2D-LC Systems}

Two-dimensional retention diagrams were created with combinations of liquid chromatography stationary phases based on molecular interactions specified in Eq. (1). An algebraic transformation of Eq. (1) was performed based on retention factor of solutes $(\mathrm{Ki})$ in Eq (2) to calculate retention indices according to [1416]

$I_{\text {Kovats }}=100 N+100 \times \frac{\log K_{i}-\log K_{N}}{\log K_{N+1}-\log K_{N}}$

Where $K_{i}$ is calculated relative to parent hydrocarbons eluting before $\left(\mathrm{K}_{\mathrm{N}}\right)$ and after $\left(\mathrm{K}_{\mathrm{N}+1}\right)$ solute $i$. $\mathrm{N}$ indicates the number of carbons of solute $i$. 


\subsection{Multidimensional Diagrams of Organic Aerosol Constituents Identified in High-Time Resolved Samples}

The methods described in sections 2.1, 2.2, and 2.4 were repeated for a total of $187,154,150$, and 149 organic compounds identified and quantified in 4 different high-time resolved ambient air samples. These newly proposed 2D-LC diagrams had advantages over Van Krevelen diagrams. Van Krevelen diagrams show the dispersion of organic aerosol components that represent ageing, oxidation, or evolution throughout the day according to environmental conditions such as type and concentration of SOA precursors, type and concentration of oxidant, ambient air temperature, relative humidity, and solar radiation. 2D-LC diagrams preserved identification of species and group them according to physicochemical properties that ultimately determined the impact of organic aerosols on the water cycle and radiation balance. These diagrams can be potentially used as means to decrease uncertainty in secondary organic production models.

\section{RESULTS AND DISCUSSION}

\subsection{Construct Structures of SOA Precursors and Products}

A selected group of 186 SOA precursors and products identified in chamber studies and ambient samples was chosen and used to represent a complex mixture of compounds with various numbers and types of functional groups that may be present in ambient air samples. The structures of these compounds were drawn with Chemdraw Professional v. 15.0.0.106 to predict the SMILES notation that was used as input to the model in section 3.2. Figure 1 shows the structures of SOA precursors and products considered in this study. The functional groups that can be observed in organic aerosols are alcohols (-OH), ketones/carbonyls $(-\mathrm{C}=\mathrm{O})$, carboxylic acids $(-\mathrm{COOH})$ and types of structures include cyclic, straight-chain alkanes, straight-chain alkenes, and aromatics. The compounds are organized in groups according to functional groups as follows: HC-hydrocarbons, A-hemiterpene, Bmonoterpenes, cA-cycloalkane, cB- 2OH, keto cycloalkane, $\mathrm{Cc}-\mathrm{OH}, \mathrm{C}=\mathrm{O}$ cycloalkane, $\mathrm{cD}-\mathrm{COOH}$ cycloalkane, cE- $\mathrm{COOH}, \mathrm{C}=\mathrm{O}$ cycloalkane, $\mathrm{cF}$ $\mathrm{COOH}$ cycloalkene, CG- $\mathrm{O}$, OH cycloalkane, $\mathrm{cH}-$ $\mathrm{COOH}, \mathrm{C}=\mathrm{O}, \mathrm{OH}$ cycloalkane, D-sesquiterpene, Ediaromatic, F- cyclic epoxide/ether, $\mathrm{G}-\mathrm{C}=\mathrm{O}, \mathrm{H}-\mathrm{OH}$ alkane, I- $\mathrm{OH}$ alkene, J- $\mathrm{COOH}, \mathrm{K}-\mathrm{COOH}$ alkene, L$\mathrm{COOH}$ aromatic, $\mathrm{M}-\mathrm{COOH}, \mathrm{C}=\mathrm{O}, \mathrm{N}-2 \mathrm{COOH}, \mathrm{OH}, \mathrm{O}-$ $2 \mathrm{OH}, \mathrm{COOH}, \mathrm{P}-\mathrm{OH}, \mathrm{C}=\mathrm{O}$ alkane, $\mathrm{Q}-\mathrm{C}=\mathrm{O}$ aromatic, $\mathrm{R}-\mathrm{OH}$ aromatic, $\mathrm{S}-\mathrm{OH}, \mathrm{COOH}$ aromatic, $\mathrm{T}-\mathrm{C}=\mathrm{O}$, $\mathrm{COOH}$ aromatic, $\mathrm{U}-\mathrm{OH}, \quad \mathrm{C}=\mathrm{O}$ aromatic, V- nitroaromatic, $\mathrm{W}-\mathrm{ONO}_{2}, \mathrm{X}-\mathrm{OH}, \mathrm{ONO}_{2}, \mathrm{Y}-2 \mathrm{ONO}, \mathrm{Z}-$ $\mathrm{OH}, 2 \mathrm{ONO}_{2}$.

\subsection{Predict the Solvation Properties of SOA Precursors and SOA Products}

The SMILES notations obtained from Chemdraw Professional were used to predict solvation parameters of SOA precursors and products shown in Figure 1. The solute solvation parameters $\mathrm{V}, \mathrm{S}, \mathrm{A}, \mathrm{E}, \mathrm{B}$, and $\mathrm{L}$ were predicted according to section 2.2. According to the separation theory, the solute retention on a chromatographic system was determined by the overall interaction of five parameters between solutes and the characteristic system. In gas chromatography, the solutes do not have hydrogen bond interactions due to their non-polar characteristic. In addition, the mobile phase is inert and did not influence the retention of the solutes. Therefore, the only parameters that influence were solute size (L), dipolarizability/polarizability (S), and polarizability from $\mathrm{n}$ - and $\pi$ - electrons (E). In Liquid chromatography, the system is more complicated due to the high polarity nature of the solutes A and B are considered, the stationary phases may have various chemistry, and the mobile phases can be mixtures of up to four different solvents with complex ranges of polarities.

The selected group of SOA precursors and products shows a wide range of compounds with various functional groups. This can be observed in the predicted solvation parameters. $\mathrm{V}$ is related to the size and shape of the molecule and is related to the cavity formation during the interactions with the stationary phase. As can be expected, the magnitude of $\mathrm{V}$ increases with carbon number. See for example the two homologous series of n-alkanes (group $\mathrm{HC}$ ) and n-alcohols (group $\mathrm{OH}$ ). The magnitude of $\mathrm{V}$ ranges $0.81-4.34$ for $\mathrm{n}$-alkanes $\mathrm{C} 5-\mathrm{C} 30$ and 0.31-4.39 for $\mathrm{n}$-alcohols $\mathrm{C} 1-\mathrm{C} 30$. $\mathrm{A}$ and $\mathrm{B}$ are related to the ability to donate or receive hydrogen bonds, therefore as has been mentioned, the values are low or zero for non-polar compounds (e.g., groups HC, A, B, D, F, G) and highest for compounds with carboxylic acid and alcohol groups (e.g., compound S115, gallic acid and cD148 cyclobutane tetracarboxylic acid). S and $\mathrm{E}$ are related to polarizability of the molecule and the values increase with the number of double bonds and the presence of oxygen atoms. For example, compounds in group Q, which are products of naphthalene oxidation, have $\mathrm{S}$ values ranging 1.38-1.78 and E 0.97-1.86. Due to these complex interactions between solutes, stationary phases, and mobile phases, it is possible that two solutes that have different number and type of functional groups show similar retention characteristics and therefore, elute similarly in space and time. 



Figure 1. Structures of SOA precursors and products identified in the literature. Adapted from Flores and Doskey [14]

\subsection{Prediction of Multidimensional Liquid Chromatography Separation}

The solvation parameter model used for distribution of solutes between two condensed phases is described according to Eq 1. By rearranging Eq. 1 and Eq. 2, Eq. 3 Is obtained:

$\log K_{i}=\frac{I_{\text {Kovats }}}{100}=\frac{\log K_{i}-\log K_{N}}{\log K_{N+1}-\log K_{N}}+N$
Where $\mathrm{K}_{\mathrm{i}}$ is calculated relative to parent hydrocarbons eluting before $\left(\mathrm{K}_{\mathrm{N}}\right)$ and after $\left(\mathrm{K}_{\mathrm{N}+1}\right)$ solute $i . \mathrm{N}$ indicates the number of carbons of solute $i$. Due to the various ranges of polarities, in this work, parent hydrocarbons used were dicarboxylic acids. Linear regression analysis of $\mathrm{V}, \mathrm{S}, \mathrm{E}, \mathrm{A}$, and $\mathrm{B}$ of dicarboxylic acids against carbon number can be used to calculate $\log \mathrm{K}_{\mathrm{N}}$ and $\log \mathrm{K}_{\mathrm{N}+1}$ as follows: 


$$
\begin{aligned}
\log K_{N} & =v\left(m_{V} N+b_{V}\right)+s\left(m_{S} N+b_{S}\right)+e\left(m_{E} N+b_{E}\right) \\
& +a\left(m_{A} N+b_{A}\right)+b\left(m_{B} N+b_{B}\right)
\end{aligned}
$$

$$
\begin{aligned}
\log K_{N+1}= & v\left[m_{V}(N+1)+b_{V}\right]+s\left[m_{S}(N+1)+b_{S}\right] \\
& +e\left[m_{E}(N+1)+b_{E}\right]+a\left[m_{A}(N+1)+b_{A}\right] \\
& +b\left[m_{B}(N+1)+b_{B}\right]
\end{aligned}
$$

Finally, the retention factor between solutes and two liquid stationary phases can be calculated by substituting equations (4) and (5) into equation (3) and simplifying as follows:

$$
\log K_{i}=\frac{v\left(V-b_{V}\right)+s\left(S-b_{S}\right)+e\left(E-b_{E}\right)+a\left(A-b_{A}\right)+b\left(B-b_{B}\right)}{m_{V} v+m_{S} S+m_{E} e+m_{A} a+m_{B} b}
$$

Linear regressions of the solute descriptors against $n$ values of dicarboxylic acids with $n=3-10$ produced slopes $(m)$ of $0.1409,0.0048,0.0164,-0.0019$, and 0.0032 , intercepts $(b)$ of $0.2574,1.0440,0.9707$, 0.3474 , and 0.6779 , and $R^{2}$ values of $1.0000,0.976$, $0.823,-0.873$, and 0.943 for $V, S, A, \mathrm{E}$, and B, respectively.

\subsection{Predict the Separation of SOA Precursors and Products in 2D-LC Systems}

In order to predict the separation of SOA precursors and products in 2D-LC systems, several stationary phases in various mixtures of solvents were considered (Tables S1-S4). This work was limited by the amount of system constants available in the literature. A mixture of systems was considered, most of them were reversed phase chromatography, in which the stationary phase is non-polar and the mobile phase is a mixture of two polar solvents. Only a few stationary phases containing cyano and diol groups were considered as part of normal-phase liquid chromatography.

The functional groups of stationary phases increase the retention of the solutes in the following order: $\mathrm{C} 18>\mathrm{C} 8>\mathrm{C} 4>$ cyano $>$ phenyl $>$ amino. The polarity of the solvent increases in the following order water $>$ methanol $>$ isopropanol $>$ dioxane $>$ acetonitrile. Increasing the amount of water in the mixture decreases retention. In this study, mixtures of water with methanol and acetonitrile were considered. According to Reta et al., 1999, both magnitude and sign of v, s, a, $b$, and $e$ are the result of the difference between stationary and mobile phases (i.e., stationary-mobile). Zero values indicate the differences of interactions between solutes and stationary and mobile phases are statistically insignificant, therefore do not considerably contribute to solute retention. Negative signs indicate the mobile phase composition has stronger contribution to retention than the stationary phase, therefore solutes will have shorter retention (i.e., will elute faster). The opposite can be said about positive solvation parameters. Reta et al., investigated the effect of mobile phase composition in systems that contain methanol and water as 45, 50, 55 and $60 \%$ methanol. As mentioned before, our work is limited by the amount of data that is available in the literature to do the modeling.
In this work we considered three mobile phase composition which are methanol:water (50:50 and 1:9) and acetonitrile:water (30:70). According to Reta et al., only $\mathrm{v}$ and $\mathrm{b}$ depend on mobile phase composition and decrease or tend to zero as methanol increases. On the contrary, s, a, and e do not vary considerably and can be said that mobile phase composition does not influence their magnitude. In addition, the systems that we have considered in this work show that $\mathrm{v}$ and $\mathrm{b}$ have the highest magnitudes. This means that solutes with large $\mathrm{V}$ values have be retained longer and solutes with large $\mathrm{B}$ values have eluted faster.

In order to find the system that provides the best resolution of the complex mixture of compounds in Fig 1, columns in Tables S1-S4 were plotted against each other to form 2D retention index diagrams in $\mathrm{LC} \times \mathrm{LC}$ systems. A total of 484, 576, 256, and 25 theoretical retention diagrams were obtained for combinations of columns in Tables S1, S2, S3, and S4, respectively. General observations are mentioned below.

\subsubsection{Stationary phases in Methanol:Water (1:1) mobile phase \\ The stationary phases in Table S3 are} octadecylsiloxane C18 (columns 1-10), octyl (column 11), phenyl (columns 12-14), and fluoro (column 1516). The predicted separation with $\mathrm{C} 18$ columns does not provide adequate separation according to groups, in some cases, the compounds are separated through the chromatogram not forming any groups. In other cases although compounds form groups, the resolution among groups is not adequate (e.g., Fig. 2).

Overall, for this system and the column selection, the combination of columns did not provide ideal separation. The best combination of columns for this system are (a) 13-1 XBridge Phenyl- SunFire C18 (Fig. 3), (b) 14-10 XTerra Phenyl- Synergi Fusion RP18 (Fig. 4), and (c) 15-10 Discovery HS F5- Synergi Fusion RP18 (Fig. 5). Although these three combinations of columns have some limitations. The column selection in Fig. 3 is able to provide separation according to groups and at the same time keeping good dispersion on both primary and secondary columns. However, although the predicted retention on the secondary column seems appropriate, co-elution of compounds within all groups is still observed.

The system in Fig. 4 provides good separation among groups, including cyclic compounds, which are normally difficult to group due to their variation in functionalities. However, the predicted magnitude on the second dimension seems too small. In real separation this has resulted in co-elution of compounds. The selection of columns in Fig. 5 provides similar separation as Fig. 3 however, the magnitude of the retention in the secondary dimension is cut by half. In this column selection, the compounds show good dispersion and less co-elution than Fig. 3, and similarly, 
cyclic compounds are difficult to groups and are shown scattered through the chromatogram (i.e., pink compounds).

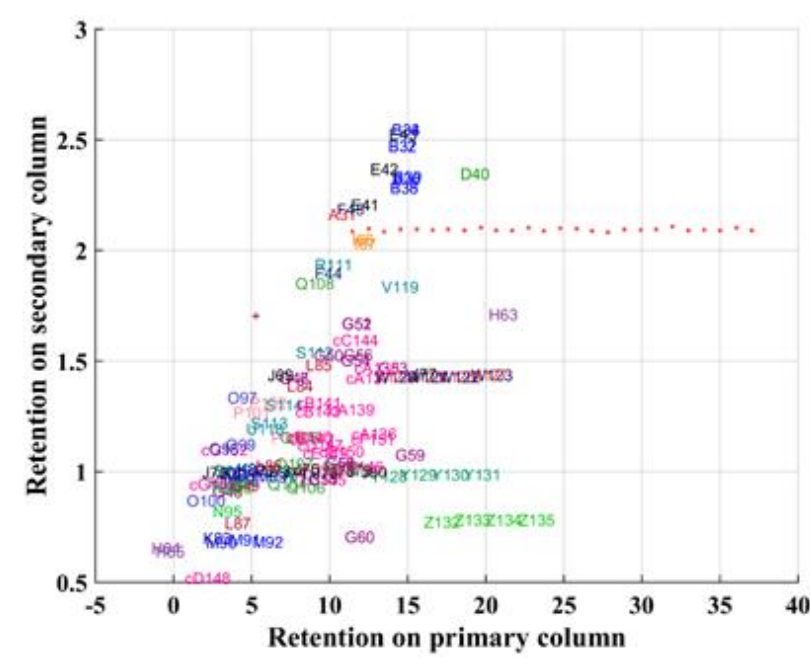

Figure 2. Theoretical LC $\times$ LC retention diagram with Betasil C18 and Discovery HS C18 as primary and secondary columns, respectively, with a mixture of Methanol:Water (1:1) mobile phase (Table S3) at $45^{\circ} \mathrm{C}$. In general, $\mathrm{C} 18$ used as a primary column $\mathrm{did}$ not provide adequate separation according to functional groups. As an example, this combination of columns did not show adequate resolution.



Figure 3. Theoretical $\mathrm{LC} \times \mathrm{LC}$ retention diagram with XBridge Phenyl and SunFire C18 as primary and secondary columns, respectively, with a mixture of Methanol:Water (1:1) mobile phase (Table S3) at $45^{\circ} \mathrm{C}$. This combination of columns provided the best separation among groups overall, on both dimensions. However, co-elution of species can still be observed.

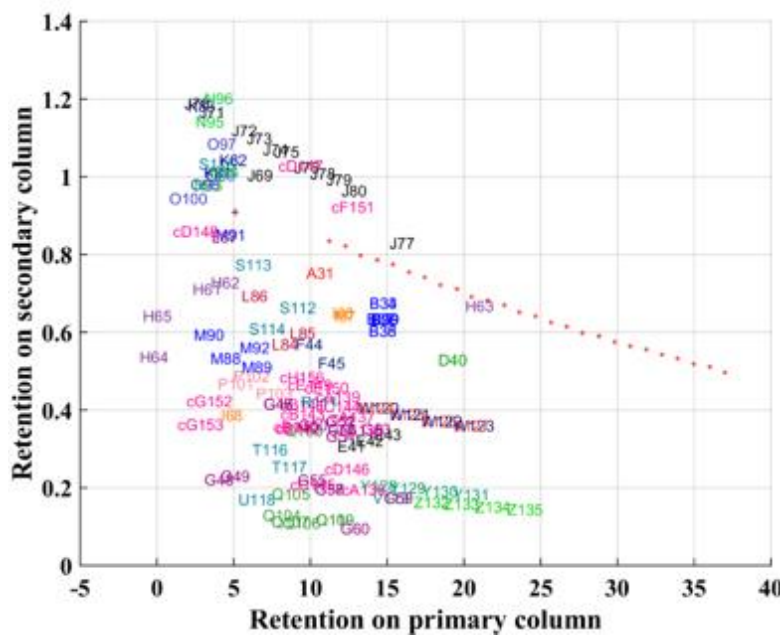

Figure 4. Theoretical LC $\times$ LC retention diagram with XTerra Phenyl and Synergi Fusion RP18 as primary and secondary columns, respectively, with a mixture of Methanol:Water (1:1) mobile phase (Table S3) at $45^{\circ} \mathrm{C}$. This combination of columns provided the best separation among groups, specially for cyclic compounds. However, the retention index on the second dimension appears to be smaller than other column combinations, which may be interpreted as possible co-elution in a real chromatographic system.



Figure 5. Theoretical LC $\times$ LC retention diagram with Discovery HS F5 and Synergi Fusion RP18 as primary and secondary columns, respectively, with a mixture of Methanol:Water (1:1) mobile phase (Table S3) at

$45^{\circ} \mathrm{C}$. The separation provided by this column combination is slightly better than in Fig 3 . However, the magnitude of the retention index of the secondary column is cut by half. Similarly to Fig. 4, this may be interpreted as co-elution in a real chromatographic system. 


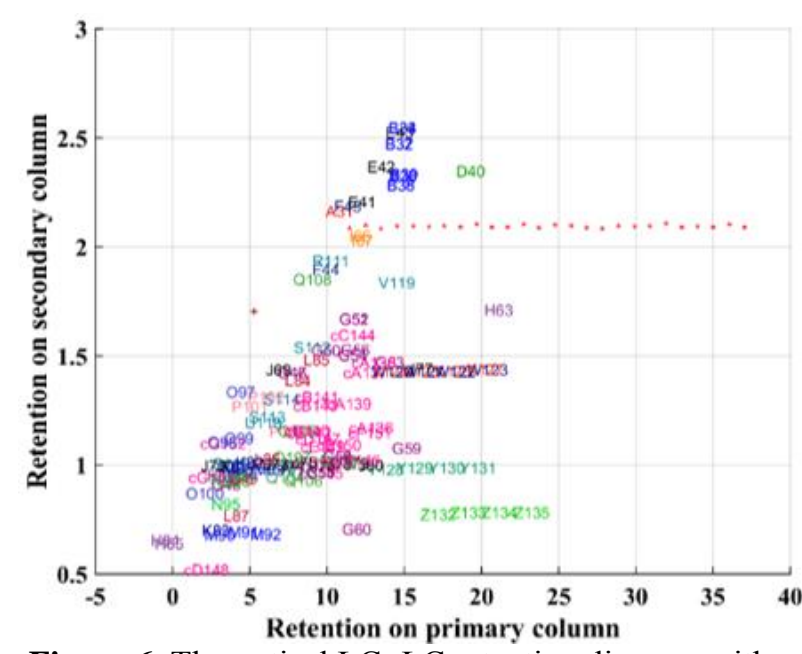

Figure 6. Theoretical LC $\times$ LC retention diagram with Betasil C18 and Discovery HS C18 as primary and secondary columns, respectively, with a mixture of Methanol:Water (1:1) mobile phase (Table S3) at $45^{\circ} \mathrm{C}$. This column combination provided good separation among groups. However, significant coelution is observed among species within the groups.

This would make difficult the identification and cuantification of species.

\subsubsection{Stationary phases in Methanol:Water (50:50) mobile phase}

For this system, 22 stationary phases were considered and a total of $484 \mathrm{LC} \times \mathrm{LC}$ theoretical retention diagrams were created. In this system, three different groups of stationary phases were considered (see Table S1): (i) dimethylsiloxane bonded phases (columns 1-8), (ii) octadecylsiloxane-bonded phases (columns 9-16), and (iii) other phases (columns 17-22). In group 2, all columns have the same stationary phase and the difference is the technology that various commercial brands use.

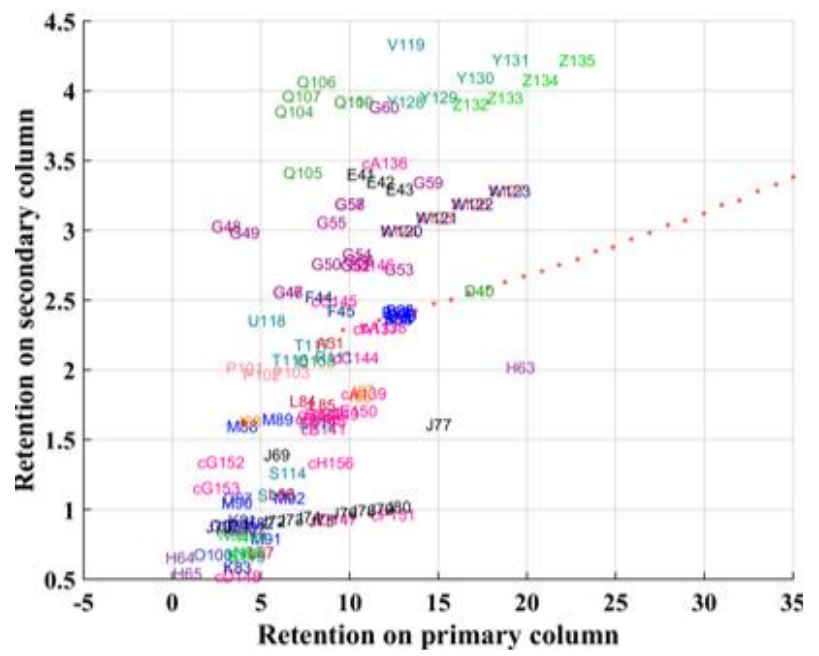

Figure 7. Theoretical LC $\times$ LC retention diagram with Cyclohexyl and Methyl as primary and secondary columns, respectively, with a mixture of

Methanol:Water (50:50) mobile phase (Table S1).

Overall, this combination of columns provided the best separation of compounds for the Methanol:Water
(50:50) mobile phase. Some advantages to the use of this system are: better resolution of compounds (1) in groups $\mathrm{Y}$ and Z, (2) cD148, K83, O100, (3) in group $\mathrm{M}$, and (4) it provides shorter analysis times due to shorter retention on the secondary column.

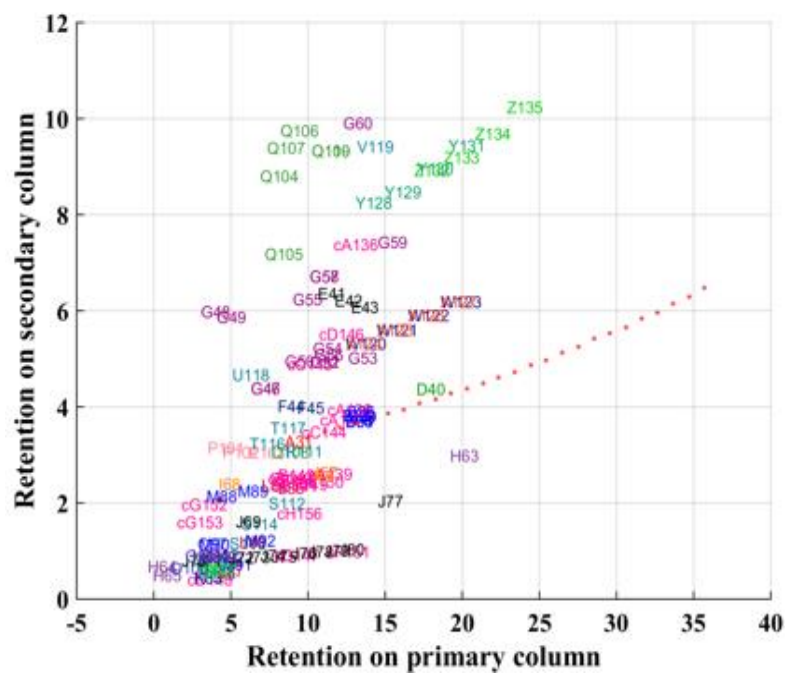

Figure 8. Theoretical $\mathrm{LC} \times \mathrm{LC}$ retention diagram with Decyl and Phenyl as primary and secondary columns, respectively, with a mixture of Methanol:Water

(50:50) mobile phase (Table S1). Overall, this combination of columns provided one of the best separation of compounds for the Methanol:Water (50:50) mobile phase system. However, the retention on the secondary column is greater than the retention obtained by the system in Figure 7.

The best combination of columns for the Methanol:Water (50:50) are observed in Fig. 7 (columns 2-1) and Fig. 8 (columns 4-7). Both combinations of columns provide very similar resolution of compounds, however, the compounds are retained longer in the system with columns 4-7. The solvation parameters of columns 2,1 and 4,7 are observed in Table 7. It can be observed that the reason why these systems provide very similar resolution is due to solvation parameters having very similar magnitude. However, although column 1 shows a slightly greater A constant than column 7, the reason for greater retention on column 7 is mainly due to more negative $s$ and $b$ solvation parameters in column 4 . This means that solutes containing high $\mathrm{S}$ and $\mathrm{B}$ will be retained in the first column for longer periods of time, therefore, will leave the secondary column later, since both columns are installed in series. Although both systems provide similar separation, there are a few advantages of choosing the system in Fig. 7 over the system in Fig. 8. The system with cyclohexyl and methyl columns (1) resolves better compounds in groups $\mathrm{Y}$ and $\mathrm{Z}$, (2) compounds cD148, K83, O100, and (3) compounds in groups $M$ and (4) it provides shorter analysis times due to shorter retention on secondary columns. 


\subsection{Diagrams of Organic Aerosol Constituents} Identified in High-Time Resolved Samples

The compounds Identified in the atmosphere by Flores and Doskey [17] in samples 2A, 3A, 4A, and 5A with $\mathrm{GC} \times \mathrm{GC}$-ToF-MS were corrected and their structures re-drawn to meet criteria for separation with $\mathrm{LC} \times \mathrm{LC}$. In addition, solvation parameters of these compounds were predicted as explained in section 3.2. $\mathrm{LC} \times \mathrm{LC}$ theoretical retention diagrams were obtained with the best combination of columns obtained in Fig. 7.

In order to facilitate the understanding of how processed the organic compound are, an additional figure that represents the organic compounds in selected bins in LCxLC diagrams was created (Fig. 9). This has advantages over Van Krevelen diagrams in which the functionalities are preserved for easy identification and organized in bins according to polarity. The analysis of Fig. 9 confirms the expected results according to observations in chamber experiments and ambient air studies. Fig. 9a was collected at 06:00-10:00h, prior to sunrise and during the first traffic of the day. This sample contains compounds that were accumulated during the night are for instance they have been already processed and contain a number of polar functionalities (i.e., see yellow bins on top-left figure). In addition, this sample contains the majority of compounds that contain single carbonyl functionalities and non-polar hydrocarbons (e.g., see light blue bins on $\mathrm{y}=2.5-3.0$ and $\mathrm{x}=0-25$ ).

Fig. 9b shows the distribution of organic compounds identified in ambient air sample collected at 10:0014:00. Due to the highest amount of radiation at this time of the day, this sample is expected to contain the highest number of aged organic compounds with multiand poli-functionalities, which are shown with dark yellow colors.

Fig. 9c shows compounds identified in a sample collected at 14:00-19:00. This sample is expected to contain a mixture of fresh compounds with no polar groups or with single polar groups emitted by traffic and aged compounds with poli-and multifunctionalities produced in the atmosphere due to oxidation reactions, which can be observed as light blue bins on $y=2.5-3.0$ and yellow and light blue bins on $\mathrm{y}=0-2.0$, respectively.

Finally, Fig. 9d shows the distribution of compounds in an ambient air sample collected at 19:00-06:00h. This sample was collected after rush hour and during $11 \mathrm{~h}$ total sampling time. Due to the lack of solar radiation, this sample is expected to contain a mixture of fresh compounds emitted by traffic and compounds that reacted later during the day but contain less polar groups than $36 \mathrm{~b}$ when the highest amount of radiation is observed. In addition, this figure shows the lack of compounds with large number of carbons $(x<20)$ possibly due to fragmentation overnight.

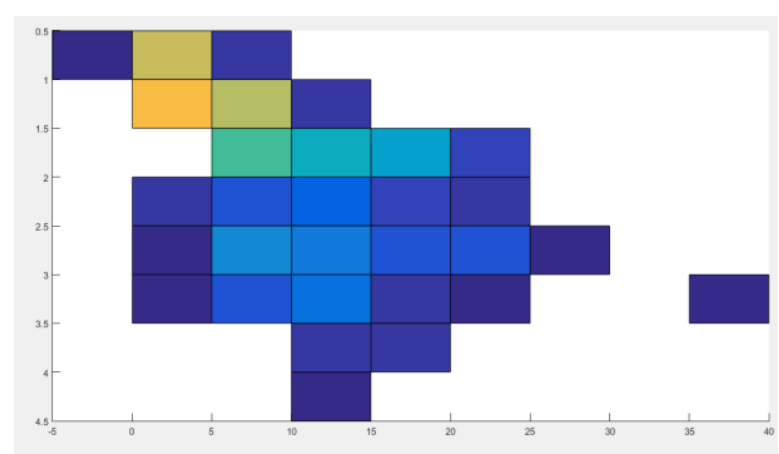

(a)

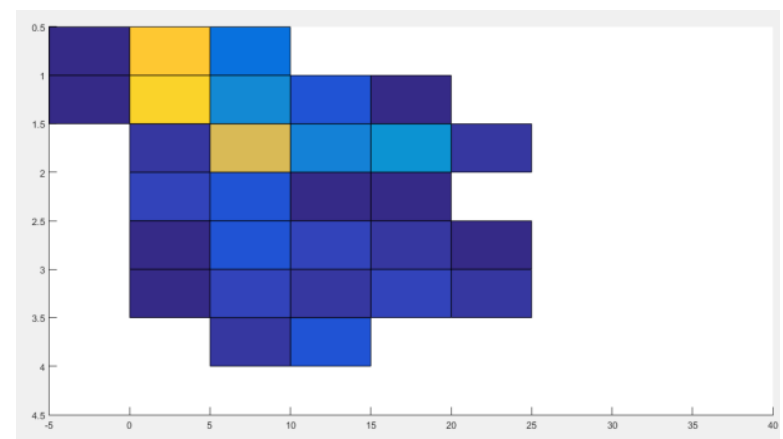

(b)

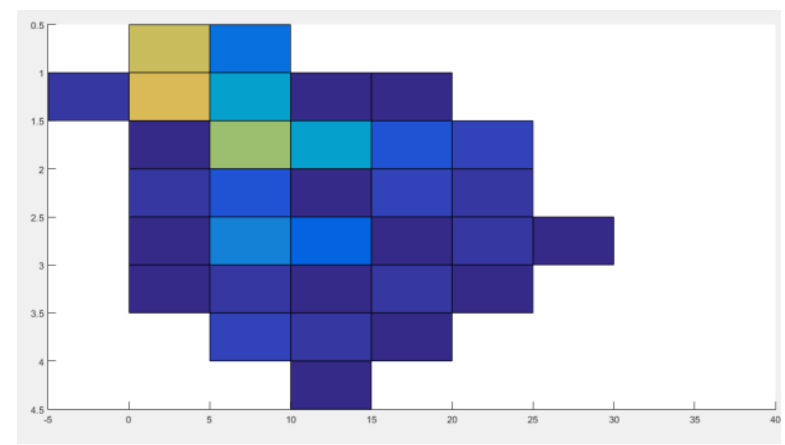

(c)



(d)

Figure 9. Theoretical LxLC diagrams of organic compounds identified in ambient air samples. (a) $2 \mathrm{~A}$ 0600-1000h, (b) 3A 1000-1400h, (c) 4A 1400-1900h, and (d) 5A 1900-0600h. The color bar indicates the number of species identified in each bin according to functional groups in Fig. 7. This figure shows the level of functionalization or aerosol aging throughout the day due to various atmospheric processes, where dark blue indicates fresh emissions (i.e, less

functionalization) and yellow indicates aged aerosol (i.e., more functionalization). 


\section{CONCLUSIONS}

The work presented here had the main objective to evaluate the use of advanced liquid chromatographic systems to resolve complex mixtures of organic compounds that are formed in the atmosphere due to oxidation reactions in the gas- and particle-phases. A model was developed and set up to generate theoretical $\mathrm{LC} \times \mathrm{LC}$ diagrams that resolve a selected number of organic compounds that have been identified in the literature. The model was used to select the best combination of columns that provides adequate separation of these compounds. It was found that most of the column combinations were not adequate and the best system was provided by methanol:water (1:1). The combination of columns that provided the best separation of the standard compounds was provided by Cyclohexyl and Methyl as primary and secondary columns. However, when this combination of columns was used to represent the evolution of ambient air organic aerosols, significant co-elution was observed. An additional figure that simplifies the separation of ambient air samples provided a simplified understanding of the distribution of organic aerosol components at different times of the day. In the near future, a detailed analysis of the LC $\times \mathrm{LC}$ diagrams of the ambient air samples presented here, and additional samples, will be necessary for detailed understanding of organic aerosol formation pathways. Finding an analytical technique that provides comprehensive identification and quantification of organic aerosol speciation is important for the evaluation of organic aerosol aging in the real atmosphere and for the improvement of organic aerosol production models. Overall, the results obtained in this work show that $\mathrm{LC} \times \mathrm{LC}$ is a promising technique that will be able to provide adequate separation of complex mixtures of organic aerosol when an adequate solvent system and combination of two stationary phases are determined.

\section{ACKNOWLEDGEMENTS}

This work was supported by The Scientific and Technological Research Council of Turkey (TÜBITAK-1002) through Project No. 116Y041.

\section{REFERENCES}

[1] Kim, S.-Y., J.L. Peel, M.P. Hannigan, S.J. Dutton, L. Sheppard, M.L. Clark, and S. Vedal, (2012). The temporal lag structure of short-term associations of fine particulate matter chemical constituents and cardiovascular and respiratory hospitalizations. Environ Health Persp, 120 (8), 1094-1099.

[2] Lu, Z., D.G. Streets, E. Winijkul, F. Yan, Y. Chen, T.C. Bond, Y. Feng, M.K. Dubey, S. Liu, and J.P. Pinto, (2015). Light absorption properties and radiative effects of primary organic aerosol emissions. Environmental science \& technology, 49 (8), 4868-4877.
[3] Seinfeld, J.H. and J.F. Pankow, (2003). Organic atmospheric particulate material. Annu Rev Phys Chem, 54 (1), 121-140.

[4] Daumit, K.E., S.H. Kessler, and J.H. Kroll, (2013). Average chemical properties and potential formation pathways of highly oxidized organic aerosol. Faraday Discuss 165 181-202.

[5] Poole, C.F., Chapter 1 - General Concepts in Column Chromatography, in The Essence of Chromatography, C.F. Poole, Editor. 2003, Elsevier Science: Amsterdam. p. 1-78.

[6] Abraham, M.H., H.S. Chadha, R.A. Leitao, R.C. Mitchell, W.J. Lambert, R. Kaliszan, A. Nasal, and P. Haber, (1997). Determination of solute lipophilicity, as $\log \mathrm{P}$ (octanol) and $\log \mathrm{P}$ (alkane) using poly (styrene-divinylbenzene) and immobilised artificial membrane stationary phases in reversed-phase high-performance liquid chromatography. J Chromatogr A, 766 (1-2), 3547.

[7] Abraham, M.H., M. Rosés, C.F. Poole, and S.K. Poole, (1997). Hydrogen bonding. 42. Characterization of reversed-phase highperformance liquid chromatographic $\mathrm{C} 18$ stationary phases. J Phys Org Chem, 10 (5), 358368.

[8] Poole, C.F. and S.K. Poole, (2002). Column selectivity from the perspective of the solvation parameter model. J Chromatogr A, 965 (1-2), 263-299.

[9] Reta, M., P.W. Carr, P.C. Sadek, and S.C. Rutan, (1999). Comparative study of hydrocarbon, fluorocarbon, and aromatic bonded RP-HPLC stationary phases by linear solvation energy relationships. Anal Chem, 71 (16), 3484-3496.

[10] Sándi, Á. and L. Szepesy, (1998). Characterization of various reversed-phase columns using the linear free energy relationship: II. Evaluation of selectivity. J Chromatogr A, 818 (1), 19-30.

[11] Tan, L.C., P.W. Carr, and M.H. Abraham, (1996). Study of retention in reversed-phase liquid chromatography using linear solvation energy relationships I. The stationary phase. $J$ Chromatogr A, 752 (1-2), 1-18.

[12] Zhao, J. and P.W. Carr, (1998). Comparison of the retention characteristics of aromatic and aliphatic reversed phases for HPLC using linear solvation energy relationships. Anal Chem, 70 (17), 36193628.

[13] Zhao, J. and P.W. Carr, (1999). An approach to the concept of resolution optimization through changes in the effective chromatographic selectivity. Anal Chem, 71 (14), 2623-2632.

[14] Flores, R.M. and P.V. Doskey, (2014). Using multidimensional gas chromatography to group secondary organic aerosol species by functionality. Atmos Environ, 96 (0), 310-321. 
[15] Seeley, J.V., E.M. Libby, K.A.H. Edwards, and S.K. Seeley, (2009). Solvation parameter model of comprehensive two-dimensional gas chromatography separations. $J$ Chromatogr A, 1216 (10), 1650-1657.

[16] Smith, R.M., Chapter 3 Retention index scales used in high-performance liquid chromatography, in Journal of Chromatography Library, R.M. Smith, Editor. 1995, Elsevier. p. 93-144.

[17] Flores, R.M. and P.V. Doskey, (In Review). Vapor- and Aerosol-Phase Atmospheric Organic Matter in Urban Air of the Midwest USA. Atmos Environ. 